\title{
Implementing interprofessional education and practice: Lessons from a resource-constrained university
}

\section{J. M. Frantz \& A. J. Rhoda}

To cite this article: J. M. Frantz \& A. J. Rhoda (2017) Implementing interprofessional education and practice: Lessons from a resource-constrained university, Journal of Interprofessional Care, $31: 2,180-183$

To link to this article: http://dx.doi.org/10.1080/13561820.2016.1261097

曲 Published online: 09 Feb 2017.

Submit your article to this journal $\pi$

Q View related articles $\sqsubset$

View Crossmark data \lceil

4 Citing articles: 1 View citing articles 


\title{
Implementing interprofessional education and practice: Lessons from a resource-constrained university
}

\author{
J. M. Frantz and A. J. Rhoda \\ Department of Physiotherapy, University of the Western Cape, Bellville, South Africa
}

\begin{abstract}
Interprofessional education is seen as a vehicle to facilitate collaborative practice and, therefore, address the complex health needs of populations. A number of concerns have, however, been raised with the implementation of interprofessional education. The three core concerns raised in the literature and addressed in the article include the lack of an explicit framework, challenges operationalising interprofessional education and practice, and the lack of critical mass in terms of human resources to drive activities related to interprofessional education and practice. This article aims to present lessons learnt when attempting to overcome the main challenges and implementing interprofessional education activities in a resource-constrained higher education setting in South Africa. Boyer's model of scholarship, which incorporates research, teaching integration, and application, was used to address the challenge of a lack of a framework in which to conceptualise the activities of interprofressional education. In addition, a scaffolding approach to teaching activities within a curriculum was used to operationalise interprofessional education and practice. Faculty development initiatives were additionally used to develop a critical mass that focused on driving interprofessional education. Lessons learnt highlighted that if a conceptual model is agreed upon by all, it allows for a more focused approach, and both human and financial resources may be channelled towards a common goal which may assist resource-constrained institutions in successfully implementing interprofessional activities.
\end{abstract}

\section{ARTICLE HISTORY}

Received 27 January 2016

Revised 12 October 2016

Accepted 11 November 2016

\section{KEYWORDS}

Biopsychosocial approach; healthcare professionals; interprofessional education; interprofessional practice

\section{Introduction}

Interprofessional education (IPE) and collaborative practice is an emerging field in the area of health professions education. It can be seen as a vehicle to address the health and social problems of our society through collaborative approaches. There is a great deal of interest in moving interprofessional collaboration forward in order to address the global burden of disease and the health disparities in South Africa. Globally, policies emphasise the importance of collaboration among health professionals with the assumption that enhanced collaboration will make better use of scarce resources and more effectively meet the complex needs of patients (Frenk et al., 2010). Higher education institutions that train healthcare professionals have a role to play in addressing these concerns (Van Heerden, 2013).

As IPE is not only an opportunity to change the way we educate future healthcare professionals but to consider how we do research and engage communities, it can be seen as a vehicle for generating change for effective healthcare. In addition, it provides an opportunity to develop T-shaped graduates that are deeply knowledgeable about their field of specialisation, yet are capable and willing to learn other skills and explore fields that may become part of their work/study for various reasons. In order to address the needs of the population, students need to become agents of change (Van Heerden, 2013). Therefore, students need to develop certain competencies. The competencies that are facilitated and aligned with the concept of T-shaped graduates during the IPE process include leadership, communication, ethics, teamwork and collaboration, conflict resolution, and patient centeredness (Interprofessional Education Collaborative Expert Panel, 2011).

Concerns raised over the years include the need to identify effective strategies to promote interprofessional education and evaluate these implementation strategies to determine if they are working (Thibualt, 2012). In addition, Abu-Rish et al. (2012) highlighted that in the absence of an explicit theoretical framework, there tends to be a disconnection between educational theories and their application to practice. The authors also highlighted that there appeared to be inconsistent reporting of study settings, populations, and outcomes for IPE activities. Additionally, the research highlights the need to consider the paradigm shift from conceptualising IPE to operationalising IPE (Barr, 2013). In addressing this, considerations also need to be given to the possible interprofessional conflicts (Agular, Stupans, Scutter, \& King, 2014). Therefore, the question of how do we address the concerns related to IPE and interprofessional practice (IPP) in resource-constrained settings such as South Africa and specifically within the Faculty of Community and Health Sciences at the University of the Western Cape (UWC) arises.

According to Waggie and Lattoe (2014), IPE and IPP offered at UWC include interprofessional core modules offered at first-, 
second-, and third-year level with primarily a theory base; exposure to an IPP-based module which includes theory and practice; and finally interprofessional world café opportunities which encompass case-based opportunities to dialogue about the inteprofessional core competencies. The various initiatives have been evaluated and will be published in the future; however, this article aims to share lessons learnt from this resource-constrained university in implementing IPE and IPP.

\section{Background}

Three core concerns linked to the implementation of IPE in this context are addressed below. Specifically, these include the lack of an explicit framework, challenges operationalising IPE and IPP, and the lack of critical mass in terms of human resources to drive IPE and IPP.

\section{Need for a theoretical framework}

Waggie and Lattoe (2014) highlighted the need for a common IPE framework at the UWC which would guide the understanding of IPE among students from first to fourth year. Based on this, Boyer's model of scholarship (1997) (Figure 1) was deemed appropriate to drive IPE and collaborative practice whilst being socially relevant to the context in which we find ourselves. Boyer's model of scholarship focuses on four areas of scholarship namely discovery, integration, application, and teaching. In proposing this model as a framework for considering IPE and IPP, it is essential to start from an understanding that collaboration does not just happen as an event but is a process that continues over time. In the application of Boyer's model, the scholarship of teaching allows us to equip students with knowledge and skills about IPE and enhance their understanding of their own profession and that of others, whilst the scholarship of application and integration allows for the facilitation of the development of skills in the real-world context and allows the students to address the needs of society in an interprofessional manner. In addition, the scholarship of discovery provides opportunity for the evaluation of the impact of strategies to facilitate IPE and IPP. Adoption of a common framework facilitates the development of a common language that emulates the competencies of IPE and IPP whilst being sensitive to the environmental context.

\section{Shift from the concept to operationalisation}

According to Barr (2013), in order to overcome the barriers to operationalising IPE, the following key principles are important and include planning together, incorporating different approaches to learning, and incorporating different professions into one faculty. Thus, to overcome the barriers of operationalising IPE/ IPP, the Faculty of Community and Health Sciences has implemented the strategies highlighted below. The faculty is uniquely positioned to drive IPE using a biopsychosocial approach as we are representative in our physiotherapy, occupational therapy, social

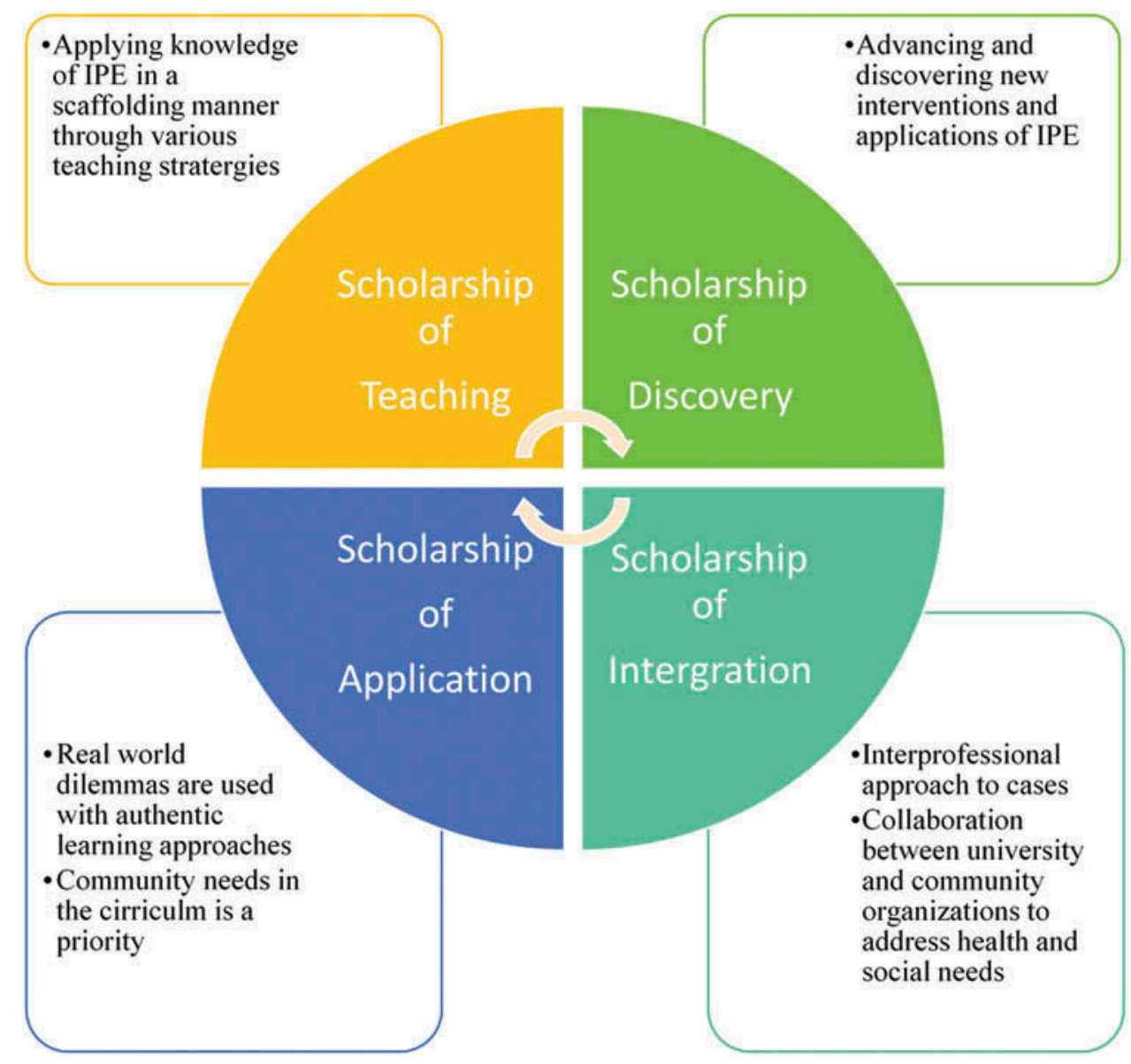

Figure 1. Using Boyer's model as a framework for IPE and IPP. 


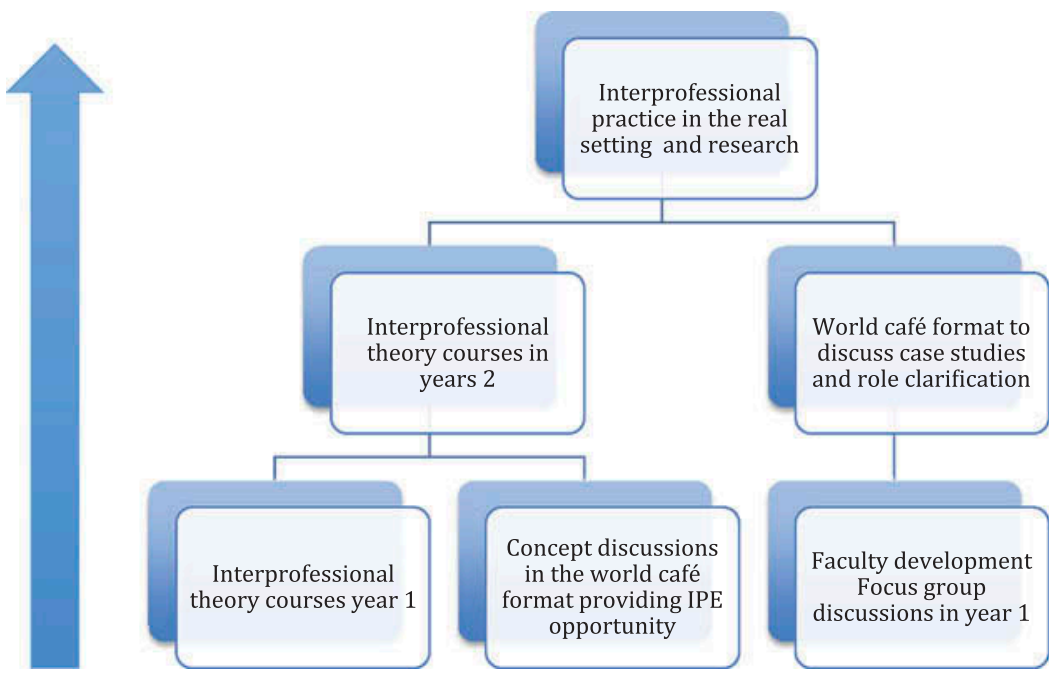

Figure 2. Scaffolding of the curriculum.

work, dietetics, exercise science, nursing, psychology, natural medicine, and public health programmes. Hence, as a faculty, we have IPE/IPP as a common vision and are able to plan our approach to IPE and practice as a collective. In order to address the challenge of different approaches to learning, we designed an IPE implementation plan using a scaffolding design and basing the learning outcomes on the six collaborative competencies, namely teams and teamwork, interprofessional communication, ethics and values, roles and responsibilities, interprofessional conflict, and interprofessional leadership. The scaffolding design (Figure 2) allows for a variety of instructional techniques that can be used to move students progressively toward a stronger understanding and, ultimately, greater independence in the learning process. It also allows for increased complexity at different levels. In the first year (scholarship of teaching), the basic concepts of IPE are presented through modules and activities such as world cafés. The second year (scholarship of application and integration) allows for the deepening of IPE knowledge and introduces IPP. The third year (scholarship of discovery) allows for the deepening of IPP knowledge and introduces research.

\section{Establishing a critical mass}

According to Steinert (2005), faculty development provides a unique opportunity to overcome barriers at both individual and organisational levels regarding IPE. Steinert (2005) further states that faculty development initiatives should target diverse stakeholders and must be based on the principles of IPE and IPP. The UWC faculty aims to demonstrate the principles and competencies of IPE (teamwork, roles and responsibilities, and communication) through collaborative teaching, research, and practice. Workshops have targeted academics, clinical educators, and service providers as continuous professional development activities ensuring that they are beneficial to both the participants and the drivers of the faculty development initiatives. The outcomes of these workshops ensured that participants had an understanding of IPE concepts and the use of conceptual frameworks to drive IPP as well as knowledge and skills that may be used to facilitate IPE and IPP.

\section{Discussion}

The Faculty of Community and Health Sciences has aimed to address the highlighted concerns regarding IPE and IPP namely the absence of an explicit theoretical framework, the shift from concept to operationalisation, and establishing a critical mass able to drive the practices of IPE and IPP. The need for a common IPE framework has been identified as an essential tool for driving IPE practices among future healthcare professionals, and thus a clear understanding of the ideal characteristics of IPE is needed to inform curriculum, enlighten professional practice, and contribute to professional development (Orchard et al., 2010; Waggie \& Lattoe, 2014). To address this need, the Faculty of Community and Health Sciences has adapted Boyer's model of scholarship (1997) to drive IPE among its various professions as it contends with the competencies of IPE and IPP while remaining sensitive to the environmental context. Boyer's model of scholarship (1997) drives IPE by enhancing an individual's understanding of application and integration, skills, and knowledge and equips individuals to address the needs of society in an interprofessional manner.

The biopsychosocial approach represented across professions within the faculty acts to drive IPE and IPP as all stakeholders embody the same vision and goal. Similarly, Illingworth and Chelvanayagam (2007) stated that collective support for IPE initiatives may drive IPE, contribute to its success, and enhance its benefits. Illingworth and Chelvanayagam (2007) has too identified preferred and different learning strategies and styles as a barrier in successfully implementing a culture of IPE. The faculty thus addressed this challenge through the use of a scaffolding 
design which teaches the six competencies of IPE and IPP. These core competencies namely effective communication, role understanding, responsibilities, teamwork, ethics, values, interprofessional conflict, and interprofessional leadership were similarly identified in literature (Buring et al., 2009; Suter et al., 2009). Last, to overcome barriers to the successful implementation of IPE, the literature highlights that faculty development initiatives should be based on the principle of IPE and IPP and target diverse stakeholders (Illingworth \& Chelvanayagam, 2007; Steinert, 2005). To address these barriers, the faculty has implemented beneficial continuous development workshops targeting academics, clinical educators, and service providers.

\section{Declaration of interest}

The authors report no conflicts of interest. The authors alone are responsible for the content and writing of this article.

\section{References}

Abu-Rish, E., Kim, S., Choe, L., Varpio, L., Malik, E., White, A., ... Zierler, B. (2012). Current trends in interprofessional education of health sciences students: A literature review. Journal of Interprofessional Care, 26, 444-451. doi:10.3109/13561820.2012.715604

Agular, A., Stupans, I., Scutter, S., \& King, S. (2014). Exploring how Australian occupational therapist and physiotherapist understand each others professional values: Implications for interprofessional education and practice. Journal of Interprofessional Care, 28, 15-22. doi:10.3109/13561820.2013.820689

Barr, H. (2013). Toward a theoretical framework for interprofessional education. Journal of Interprofessional Care, 27, 4-9.

Boyer, E. (1997). Scholarship reconsidered: Priorities for the professoriate. San Francisco, CA: Jossey-Bass.
Buring, S. M., Bhushan, A., Broeseker, A., Conway, S., Duncan-Hewitt, W., Hansen, L., \& Westberg, S. (2009). Interprofessional education: Definitions, student competencies, and guidelines for implementation. American Journal of Pharmaceutical Education, 73(4), 1. doi:10.5688/ aj730459

Frenk, J., Chen, L., Bhutta, Z., Cohen, J., Crisp, N., Evans, T., ... Huda, Z. (2010). Health professionals for a new century: Transforming education to strengthen health systems in an interdependent world. The Lancet, 376(9756), 1923-1958.

Illingworth, P., \& Chelvanayagam, S. (2007). Benefits of interprofesisonal education in health care. British Journal of Nursing, 16(2), 121-124. doi:10.12968/bjon.2007.16.2.22773

Orchard, C., Brainbridge, L., Bassendowski, S., Stevenson, K., Wagner, S. J., Weinberg, L., ... Sawatsky-Grilling, B. (2010). A national interprofessional competency framework. Vancouver, BC: Canadian Interprofessional Health Collaborative.

Panel Interprofessional Education Collaborative Expert. (2011). Core competencies for interprofessional collaborative practice: Report of an expert panel. Washington, DC: Interprofessional Education Collaborative.

Steinert, Y. (2005). Learning together to teach together: Interprofessional education and Faculty development. Journal of Interprofessional Care, 1, 60-75. doi:10.1080/13561820500081778

Suter, E., Arndt, J., Arthur, N., Parboosingh, J., Taylor, E., \& Deutschlander, S. (2009). Role understanding and effective communication as core competencies for collaborative practice. Journal of Interprofessional Care, 23, 41-51. doi:10.1080/13561820802338579

Thibualt, G. (2012). Interprofessional education in USA: Current activities and future directions. Journal of Interprofessional Care, 26, 440441. doi:10.3109/13561820.2012.704778

van Heerden, B. (2013). Effectively addressing the health needs of South Africa's population: The role of health professions education in the 21st century. South African Medical Journal, 103(1), 21-22. doi:10.7196/ SAMJ.6463

Waggie, F., \& Lattoe, N. (2014). Interprofessional exemplars for health professionals programme at a South African University. Journal of Interprofessional Care, 4, 368-370. doi:10.3109/ 13561820.2014 .891572 